\title{
A Centralized Strategy to Collect Comprehensive Institution- wide Data from Faculty and Staff about Community Engagement and Public Service
}

\author{
Emily M. Janke and Kristin D. Medlin
}

\begin{abstract}
"How do I get faculty and staff to record information about their community engagement and public service activities, partnerships, and contributions?" This article describes one institution's strategies to collect comprehensive community engagement and public service data through a centralized system. Beyond what metrics to collect, we present insights about who to talk with, questions to prepare, and conversations that will increase participation from faculty and staff to report their activities annually.

The past decade has witnessed an increase in the number of requests of higher education institutions to report information about community engagement and public service activities, ranging from mandatory to elective. Mandatory pressures include the university regional accreditations and requests from legislative or governing bodies for accounts of how the university is interfacing and partnering with and, thus, contributing to the public. For example, "community/public service" is a core measure of "institutional effectiveness" (Requirement/Standard 3.3.1.5) by the Southern Accreditation of Colleges and Schools Commission on Colleges, similar to other regional accreditations that require institutions to document the nature, scope, and intended constituents of the programs and public services provided by the institution (see North Central Association of Colleges and Schools, The Higher Learning Commission, Core Component 1.B).

Some states and state systems are increasing requirements for information about institutional involvement with and contributions to communities. For example, in 2013, the University of North Carolina (UNC) system established annual reporting requirements across its sixteen campuses to "track progress in community engagement and economic development"; these indicators are published annually in a UNC Engagement Report (see Janke 2014 for a complete description of the criteria established for choosing metric areas). In Massachusetts, the Board of Higher Education has named civic education and engagement as the sixth goal of the state's Vision Project in 2012, precipitating conversations about tracking and measuring students' civic activities and outcomes.
\end{abstract}


Increasingly, institutions are choosing to respond to elective opportunities to report community engagement and public service activities. Hundreds of colleges and universities have applied to Carnegie Foundation's Elective Classification of Community Engagement, The President's National Higher Education Community Service Honor Roll, and the Washington Center's Higher Education Civic Engagement Award. Hundreds of institutions complete Campus Compact's national survey, and increasing numbers are submitting to the Community-University Engagement Awards established by the Association of Public and Land-Grant Universities (APLU) and the Engagement Scholarship Consortium (ESC), with support from the W. K. Kellogg Foundation.

Further, offices internal to institutions of higher education are experiencing a greater need for comprehensive portraits of how faculty, staff, and students are collaborating with and serving the public. Telling the story of institutional engagement has become a key interest and activity within offices of university relations, development and advancement, and government relations (Weerts 2011; Weerts and Hudson 2009) to achieve fundraising, friend-raising, and public recognition and fiscal sustainability goals.

Campuses that have been required to or that have elected to respond to requests for data related to campus-wide community engagement and public service activities and outcomes are familiar with the costs incurred, particularly the faculty and staff time to communicate, record, review, synthesize, and formally report information as well as the expense (both time and money) of adapting, creating, or licensing software systems to facilitate the collection, storage, and analysis of data. Administrators tasked with developing the report also know the political costs associated: the cost-benefit analysis of asking faculty and staff to provide pieces of information not previously collected for what is often perceived as "administrative purposes." Given the increased demands for counting, accounting, and reporting on activities across nearly all areas of faculty work, which have increased the administrative portion of faculty workloads, administrators are asking, "How am I to add this to their load? What will be the cost in asking for this data?"

\section{A Strategy to Collect Data Centrally and Comprehensively: A Case Example}

Accounting and accountability across all mission areas of higher education, including public service and community engagement, are likely to continue to increase (Holland 2013). Therefore, it is essential to take a scholarly approach to developing a strategy to collect data if one is to gain adequate participation (or compliance, if mandated) in ways that minimize confusion, frustration, or contestation. It is also useful to learn from others who have attempted this work previously to identify strategies as well as challenges experienced.

The authors of this article have been working to establish a strategy to collect comprehensive, institution-wide data on members' engagements with and service to external communities since 2010 at the University of North Carolina at Greensboro 
(UNCG). While increased accounting pressures described above have certainly played a role in catalyzing institutional investment in data collection, UNCG has experienced an acute and immediate need for quick, accurate, and precise data due to increased scrutiny and oversight of the UNC system board of governors and decreased state appropriations for the UNC system campuses. In particular, UNC campuses have needed to quickly fill information gaps about who is doing what, where, when, and with whom across university-wide centers and institutes, but also increasingly in the curriculum as well. Previously, UNCG had no central system to track the full scope of institutional contributions offered by faculty and staff members' activities and work with and for external constituents. Tracking community engagement and public service is especially challenging at large, urban metropolitan universities, as is true for UNCG which serves over 18,000 undergraduate and graduate students across seven academic units in over fifty academic departments.

As context, it is useful to note that beyond the economic and political pressures described above, UNCG had already committed itself to increasing support for community engagement and public service in a variety of ways. Several key indicators of this commitment include the 2009-2014 UNCG Strategic Plan, which explicitly supported community-engaged scholarship, civic responsibility, and community service as key goals. In 2010, the faculty had voted to incorporate explicit recognition for community-engaged scholarship in promotion and tenure policies throughout the teaching, research/creative activities, and service profiles. UNCG was classified as a "community engagement institution" by the Carnegie Foundation in 2008, and was reclassified in 2015.

In 2010, UNCG appointed Emily M. Janke (author) to lead the Community Engagement Initiative to establish a vision and plan for supporting excellence in community engagement. As a result of the process which included a thirty-member advisory panel with faculty, staff, students, and administrative and community leadership, the Institute for Community and Economic Engagement (ICEE) was established in 2012 with a full-time director (author Janke) and graduate student (author Medlin).

One specific element of the 2009-2014 university strategic plan activated by ICEE was "to embed into existing [data documentation methods], and where necessary, establish new, systems for tracking and assessing the broad range of community-engaged activities, programs, and initiatives across the university" (ICEE 2013, 3). A second related element was to serve as the central communication hub for community engagement activities, relationships, resources, scholarship, best practices, and outcomes. This work included communications with academic affairs, student affairs, and administrative offices campus-wide to deepen, to make more pervasive, and to integrate community engagement into core academic work and systems for the purpose of advancing strategic institutional and community missions and goals. In recognition of the important and essential interconnections between scholarship, teaching, and economic, cultural, and community engagement, the director of ICEE reports to the vice chancellor for research and economic development in the Office of Research and Economic Development. 
The strategies shared here were developed and have continued to be refined since 2010 by ICEE's director and graduate student, who later served as a full-time staff member for two-and-a-half years. Today, data collection continues under the direction of the lead author (now serving as part-time director and tenure-track faculty member with teaching and department responsibilities) and a twenty-hour graduate assistant. Administration of campus-wide data collection has become more streamlined, though it still requires informed and proactive attention from administrative leadership, as described later in this chapter. While each institution will need to develop an approach that attends to its own unique context, structures, and dynamics, we discuss some key lessons learned, especially the value of creating person-to-person meetings that attend to the questions of why, what, and how as they relate to reporting community engagement and public service activities.

\section{Insight \# 1: Collect Everything at One Time}

To increase the feasibility of reporting data, the institute was committed to creating a single "ask" for data, compiling the various requests for data into a single form. To make the collection and reporting of community engagement and public service data most efficient, the institute staff reviewed all past, future, and likely requests for data about the university's connections with external communities, including data needs for institutional accreditation, Carnegie's Elective Classification of Community Engagement, the President's National Honor Roll for Community Service, and the University of North Carolina system's annual metric requirement.

In tandem with this review, we also spoke with a number of units across campus that have responsibility for collecting and/or reporting information about various aspects of community engagement and public service, including the Office of Leadership and Service-Learning (President's National Honor Roll for Community Service), the Office of Institutional Research (UNC System Engagement Report), and the Office of Assessment and Accreditation (Southern Accreditation of Colleges and Schools). We also spoke with the Undergraduate Research, Scholarship and Creativity Office to ensure that we were tracking relevant community-based undergraduate research opportunities. We reviewed existing surveys and databases used by offices internally to collect data to determine what systems we could adopt to make comprehensive university-wide data collection most feasible. Over the years, faculty had experienced increasing requests for data from multiple offices that, while distinct from each other, seemed to many faculty as redundant of previous requests.

Because the full scope of an institution's contribution to the public is the combination of community engagement partnerships and public service activities - and various requests and reports often require specific data that are often slightly different from each other (for example, whether to report student hours, faculty participation numbers, or location of the service by county) - the institute staff cast a wide net, collecting both community engagement and public service data. We used the term community engagement, using the definition provided by the Carnegie Foundation: "communityuniversity reciprocal partnerships that build the capacity of university and community 
partners for mutually beneficial outcomes" (Carnegie Foundation for the Advancement of Teaching n.d.). This term was defined and adopted at UNCG as a result of conversations about promotion and tenure in 2010. Likewise, we used the term public service to describe activities that were relatively more unilateral and unidirectional in the sense that the university provides services to the public, such as access to library services, lectures and other special events, community service opportunities, and access to facilities (Kellogg Commission 2001). The key distinction, we pointed out in all communications, is that community engagement requires the reciprocal exchange of knowledge enacted through partnership, whereas public service does not.

Collecting data about both community engagement and public service proved to be essential. It was critical to collect both types of activities if we were to tell the full scope of the institution's contributions to the wider community. Both forms of service and engagement provide significantly and meaningfully to the health, safety, and vibrancy of our communities. Further, accreditations, awards, recognitions, and annual reports request information about activities that are done in partnership with communities, as well as those in which activities are provided to the community by the university.

Not least of all, it was important to demonstrate that each of these activities was valued at the university. In the earlier conversations we had with faculty related to the documentation and evaluation of community engagement in promotion and tenure policies and practices, we had identified the tendency for individuals to assign relative and dichotomous value between the two ("community engagement is more valuable than public service"). It was important that we collected both at the same time to indicate the importance of both as meaningful contributions to communities, even though each has different processes, outputs, and outcomes. Partnerships may have elements of both public service and community engagement at different times and for different goals; and, the whole may be greater than the sum of its parts.

\section{Insight \#2: In-Person Meetings to Create Awareness and Buy-In}

In our experience, we found that we needed to create an intentional plan - a plan that, in many ways, is reminiscent of community organizing practices. We needed to gain awareness, recruit allies, and encourage participation to our "cause." We found that successful implementation of such strategies and data collection efforts required active leadership and constant and consistent communication from the top-down (e.g., provost to faculty) and "middle-out" (e.g., ICEE to administrative assistants and faculty). We started with senior academic leadership, and then moved to direct communication with department and program chairs and faculty.

At the "top," the provost provided key support to the data collection initiative in several ways. First, the provost invited the ICEE director to present the request and requirements for community engagement data reporting at the bi-weekly meeting of deans. At this meeting, the director presented requirements for the data collection (accreditation, recognitions) as well as opportunities to inform strategic connections and directions for the university - what could this data tell them, and how might it be 
an asset to their own agenda? This meeting was important because it established awareness of the data collection initiative, as well as an opportunity to share the uses of the data - or why data matters. This top-down approach helped the deans to understand the importance of the data collection as a university initiative and provided important recognition of the context in which the provost later sent out an email request inviting all faculty and staff to participate in the data collection initiative.

Enacting a middle-out approach, the ICEE director authored an email that the provost sent as a formal university-wide request for faculty and staff to contribute community engagement and public service data. Deans were instructed to share the request with department chairs and center directors and other staff whose participation would be required. In the letter, ICEE also requested working meetings with those individuals who would most likely be reporting or coordinating reporting efforts within the unit such as the associate dean of research, department chairs, and internship and placement coordinators. Following this request from the provost, ICEE staff initiated direct contact with a key administrative leader within each academic unit asking for support to convene a meeting for their unit. The purpose of the meetings within each unit was to create a single and unified conversation about why the data was needed, what data was to be reported, and how to report data into the online mechanism.

If one were to expect that a mandate sent by the provost (or even, the president or chancellor) were to be sufficient for generating widespread participation in a data collection initiative, one would be sorely disappointed and quickly disillusioned. Meeting with each unit to discuss the content and process for data reporting was essential to recruit participation in this comprehensive data collection effort across the university. First, they were necessary for communication and information dissemination, given the variable responses of the deans with regards to coordinating conversations with key people within their units. For example, one dean sent an email with the request to key individuals within the unit and helped to launch the process by identifying a point person to help collect information unit-wide. In most other cases, ICEE staff members initiated contact with unit administrators directly (typically the associated dean of research and the internship coordinators) to prompt the meetings. This was essential as there were many cases in which department chairs were unaware of the request from the provost, although it is not clear whether the message was not sent by the dean or if the department chair had missed or misinterpreted the email request. Regardless of the cause, direct and proactive communication between ICEE staff and academic departments was crucial. Just as community organizers emphasize face-to-face meetings to generate awareness, understanding, and buy-in, we found that we needed to spend considerable time in conversation with those we hoped to participate in the data collection initiative.

\section{Insight \#3: Prepare for the Three Essential Questions: Why, What, and How}

In our analysis of the first few meetings with executive leadership, as well as with faculty and staff who were to directly report or coordinate the reporting of community 
engagement and public service data, we found that they followed similar arcs with regard to the questions and topics raised. These can be summarized into three questions: [1] Why is this data being collected?; [2] What data is to be reported?; and [3] How are we to report this in a way that is accurate and feasible given limited time of the faculty and staff who do this work and know the data to report? We discovered that predicting and planning for these three overarching questions was key to introducing faculty and staff to the data collection initiative and to "convert" them from being unwilling skeptics who challenged the utility and reasonableness of the effort to willing participants who understood the value of their contributions - or why the "juice (data) was worth the squeeze (effort)" (Janke 2014).

\section{Answering the Why}

"Why do we/I need to report this information?" was the most frequent question we heard. Before we discuss the various answers we provided to this question, it is important to understand the meaning- making and motives behind this question "Why?" in the first place.

First, individuals who were asking "Why?" wondered about who the audience was for receiving information, and more importantly, what assumptions that audience would make about this information - How might they use it? What aspects of this work will be most valued, least valued, or undervalued? Our experience and scholarship on organizational management demonstrates that requests for information, whether they are ad hoc or integrated into ongoing reporting structures, are experienced as valueladen: individuals interpret information requests as indicators of what is valued by the entity asking for them (Price, Gioia, and Corley 2008). Thus, seemingly simple requests are interpreted by institutional members to be indicators of what they ought to be doing (or what someone else thinks they ought to be doing). For these reasons, data collection is important strategic work and must be handled carefully to minimize confusion, or worse, contestation, among those who are expected to provide the data. Administration of data collection initiatives must attend to various dynamics, including how messages are sent, received, and interpreted by those whose participation is critical.

Second, understanding "Why?" allows one to calculate an individual cost/benefit analysis. This will take my time, so what is the payoff? Will this help me directly, or will this help the institution more generally? These questions relate to one's individual identity and image within the institutional context: Is my work valued as a member of this organization? How do I ensure that I present myself in the most positive way?

As demonstrated here, data collection and reporting prompts meaning-making (Price, Gioia, and Corley 2008). More specifically, asking faculty and staff to report information about their community engagement and public service activities encourages them to think deeply about this request in the context of other institutional initiatives and current events and leads them to consider questions about the value of this type of work. Therefore, being aware of and proactively designing a strategy to address these questions is critical if faculty and staff are to be convinced of the value of their participation. Although each conversation was unique given the characteristics, 
motivations, and priorities of the unit, each tended to touch on several of the points described by Janke and Holland (2013) in "Data Matters!," a two-sided flier developed to summarize the strategic benefits and uses of engagement and service data.

In these meetings with key administrative, faculty, and staff stakeholders, we addressed the "Why?" question drawing on various institutional priorities that might be of particular relevance to specific audiences. In this way, there was an element of improvisation, choosing what aspects would resonate with a group of people, while drawing on previously rehearsed ideas. Other institutions may find alternative or additional touchstones that are effective with their various stakeholders.

Accountability. We reminded faculty and staff that while we have become accustomed to, and even accepted as necessary and as good practice, rigorous reporting, evaluation, and monitoring of teaching and research, recently increased attention and accountability has extended to the public service part of the university's mission. In the past, institutions of higher education did not have to report on their contributions to the state, and therefore, annual reporting mechanisms do not routinely ask about these activities. An emphasis on engagement and service accountability has been reinforced as external recognitions such as the Carnegie Elective Classification of Community Engagement, and the President's National Community Service Honor Roll require reporting and monitoring of engagement and service data. Accreditation changes, as well as expectations from the public and the UNC system, have changed that for us as well.

Claiming the Recognition We Deserve. The phrase, "UNCG is a best kept secret," is heard commonly across campus from faculty, students, staff, administrator, and alumni. In our conversations, we point to the importance of this initiative as it collects immediately accessible and real stories to assist in claiming and receiving the recognition that institutional members believe is deserved but not yet realized.

We remind faculty and staff that the data they report does not go into a filing cabinet in a locked room, never to be seen again, but instead, that we would ensure it was accessible by those allies on campus who were committed to helping tell their story. University relations staff are grateful to be kept up to speed on where innovative and exciting community-university projects are taking place, so that they can publicize them when and where it is appropriate. Government relations staff are able to advocate on behalf of activities that are working to affect policy or systems at the local, state, or federal levels.

Generating Revenue. Claiming recognition for community contributions is especially important, we point out, to development and advancement officers to fundraise for teaching, research, and service. Development and advancement officers have described to us the difficulty and frustrations they experience trying to keep a "pulse" on what exciting things are happening within the classrooms, the labs, communities, and other venues in which faculty, staff, and students are contributing meaningful work - work that others would want to know about and potentially fund. A central system that 
collects information university-wide creates a conduit between faculty and staff to development officers that would not otherwise exist. As one colleague in development noted, "In university advancement, we create little 'cheat sheets' within the various units so that we know who to talk about or bring with us when we meet with potential donors who want to support a particular cause or activity."

Further, demonstrating the contributions to the community has been an important tool in capital campaigns as universities must pursue increasing proportions of their budgets from non-state funds. Other institutions, such as Indiana University-Purdue University Indianapolis (IUPUI) and Tulane University have both yielded successful capital campaigns drawing on their communities and regions as funders, beyond their alumni.

Likewise, comprehensive and accurate understanding of community engagement and public service activities helps faculty and professional staff to identify opportunities for interdisciplinary and cross-sector funding - an increasingly common and sometimes required component of grants, contracts, and awards.

Facilitating Connections and Collaboration. Creating a "central mind" about the services and resources that are available from across the institution to the broader community is essential if we are to become more accessible to communities. UNCG has always received calls from the community asking for help or for information, and too often those inquirers found themselves at a dead end, frustrated at the lack of care taken to help them, and giving up on working with UNCG forever. We share this story with colleagues to emphasize that by collecting engagement and service data, we are better equipped to respond to requests for information or collaboration from the community. We are able to more quickly pull together interdisciplinary teams of faculty, staff, and students who may be able to inform a particular community topic or concern.

Further, we realized that while various units across campus were committed to many events or activities (such as camps, school workshops, etc.) that were open to the public, there was no central directory for community members to access quickly. We worked to centralize and curate this list of publicly accessible resources online (http:// communityengagement.uncg.edu/referral-desk), so that members of the community do not have to look across all websites to find information. At UNCG, a referral desk was established in ICEE and has been used to receive and address over 150 inquiries from the community since it was first launched nearly two years ago. The community engagement and public service data provided by faculty and staff provides the essential foundation of information required to offer such a service.

Recruiting and Retaining Students, Faculty, and Staff. We found that in talking with prospective faculty and staff, they were considering the possible community organizations they could work with as part of their decision to choose UNCG. Collecting and showcasing engagement and service data allowed prospective employees the ability to examine the current activities that were taking place between faculty, staff, and students and the community and imagine what relationships they could build or what existing projects they could easily join. One prospective faculty 
member shared that she had viewed The Collaboratory ${ }^{\circledR}$ [online database of community engagement and public service activities] prior to her on-campus interview for a tenure-track faculty position. She shared that she identified specific people and partners that she was interested in speaking to, and potentially, working with, should she come to UNCG. The Collaboratory ${ }^{\circledR}$ thus helped her to develop very clear and specific questions about what could be possible at UNCG and to envision a future for herself as a community-engaged scholar at UNCG. This message resonated during our conversations requesting information, as it helped department chairs and other leaders understand how they could proactively shape the message being sent by their unit about both the rich relationships that are developed at the personal level with community and the supportive and inclusive culture fostered by the unit.

Similarly, students are increasingly viewing UNCG as a place they can come to make a real difference in the world. UNCG's recent marketing campaign touted the tagline "Do Something Bigger Altogether" and frequently highlighted the unique experiences students could have at UNCG and the work they could accomplish by partnering with and serving the community throughout their entire college career.

Strategic Planning. Related to recruiting and retaining faculty, staff, and students is the potential for engagement and service data to inform strategic planning initiatives. Particularly, this data informs and clarifies goals for community engagement as a teaching pedagogy as well as an approach to research, creative activities, and public service, all of which serve to achieve key, institutional strategic goals.

For example, what impact areas do we want to specialize in; be known for; and attract, recruit, and retain students, faculty, and staff in? Do we want to establish a few deep, long-term, multi-dimensional and multi-stakeholder partnerships, or continue to maintain a lot of smaller and individual partnerships? How do our projects in community align (or not) with larger university strategic priorities and initiatives? How do faculty and staff activities and scholarly strengths align with community priority areas? How many of our students are being reached by the community, and vice versa? What are our targets for engagement? What forms of activity do we want our community engaged in with our students?

Research, Assessment, and Benchmarking. One clarification we routinely had to make during our conversations was that collecting engagement and service data was the important first step of an involved and longitudinal scholarly process. Identifying the landscape of UNCG's activities in the community laid a solid foundation for more sophisticated research, assessment, and benchmarking strategies that would allow us to track progress toward some of the goals identified above. By knowing more about what community-university activities existed, we would then be able to establish some key common indicators across activities that would let us begin to talk about impact on a variety of stakeholders, asking questions such as: Does community-engaged learning positively impact students' academic, personal, professional, and civic development? Do community-engaged research and other strategic initiatives improve faculty and staff productivity and retention? 
Having access to this data allowed UNCG to begin to examine its role as a member of the community, contributing to shared initiatives as just one member at a larger community table. We hope to begin to understand how, if at all, UNCG contributes to "moving the needle" on community priorities. For us to achieve this, we must move, as Holland suggests, from collections of individual and coincidental activities to collective and intentional partnerships (Janke 2014). Having this engagement and service data allows UNCG to begin examining questions such as: Do communityuniversity partnerships improve the quality of life across a number of key community indicators like education, health, safety, or economic development?

In almost all meetings, our response to the "Why?" questions almost always includes a careful selection of the reasons addressed above. The order in which these uses are presented depends on the audience and the motivations that are likely to drive their willingness to enter records of their community engagement and public service activities.

\section{Answering the What}

The "Why?" questions were typically followed by the "What?" questions: What specific data are you asking me/us to report? What are your definitions of this work? As described earlier, ICEE was committed, to the extent possible, to creating a unified request within a single mechanism to collect information about community engagement and public service. This was done by identifying existing, as well as anticipated, reports, awards, accreditations, and other requests for data that are collected annually and regularly, or were fairly predictable given previous requests. Therefore, the surveys and (later) database included descriptions of:

- Basic project details such as description, dates, locations, and primary contacts

- Information on the faculty or staff person submitting the data (department, appointment, demographic information)

- Partner/participant information (at the organizational and individual levels)

- Areas of impact and forms of activity

- Forms of student involvement

- Assessment efforts related to the activity

- Current funding

- Resulting outcomes for the institution and for the community

The biggest challenge across our conversations was to convince faculty, staff, and administrators that this level of detail was necessary and that by only asking for this data one time (and then sharing with all the other offices that needed the data) we were actually increasing efficiencies. We argued that while the time taken to input this data at one time may be significant, they were actually saving time and reducing redundancies in the long run. These requests for data will not go away, and we are doing our best to curate these into a single "ask."

Curating Frequently Asked Questions. Throughout the meetings with faculty and staff we heard a number of questions that were asked repeatedly. For the sake of consistency, as well as efficiency, ICEE staff collected these questions asked at meetings and via email correspondences, wrote answers, and posted them as FAQs 
(frequently asked questions) on the institute's webpage dedicated to the annual data collection initiative.

From a technical perspective, there were a number of frequently asked questions about either content or process. Intentionally collecting and posting these technical-related FAQS online helped to streamline questions, thereby minimizing inquiries and time spent by the institute staff responding to them. The Frequently Asked Questions website has been visited over two hundred times since its creation in March 2015, and visitors spent an average of five minutes on the webpage, suggesting that they found value in the content provided (ICEE 2015). These included data collection basics such as:

- Who should report data?

- Can I ask my administrative assistant to complete the information on my behalf?

- What if I have a lot of different activities to report?

- How is the data being collected?

- What office is leading the data collection effort?

- I worked with someone else on campus - how do I avoid duplication of reporting?

- I'm having trouble with the survey or database- who can I call for assistance?

- Can I save a copy of my survey for my own records?

- Who will have access to the data I report?

- What years of activity should I report?

Other questions were related to terminology and guidelines for what kinds of activities to report and how. These frequently asked questions included:

- What is community engagement?

- What is public service?

- Who is "community?"

- Who is a "partner?"

- Should I report service on a community board, media interviews, or invited talk?

- Should I report music, theater, dance, or other kinds of performances?

- Should I report camps, public lectures, and other events made available to the public?

- Should I report professional development or continuing education?

- Should I report internships or practicums?

Establishing responses to these types of questions were more challenging as they necessitated a degree of interpretation to categorize community engagement and public service activities as discrete, though often times related, activities. It was helpful, if not necessary, to our efforts that the director of the institute had previously been tasked by the provost to help establish definitional guidelines for community engagement and public service for the university in 2011. Though never formally adopted by the faculty senate, they have operationally served as the university's guidelines to define community-engaged teaching, community-engaged research/creative activity, community-engaged service, and public service. They are posted on the provost's university-wide promotion and tenure policy and documents site (UNCG 2010). They also explain the operational definition of "community" and "partner." 
Whether institutions choose to collect data on internships, performances, camps, and community board service will depend on how the data will be used and by which units and offices. In all cases, we emphasized that the service must have been done as a UNCG representative and not as an individual citizen. We have included the FAQs and some of the responses at the end of this article (see Appendix) to make transparent our choices. Institutions may be well served by reviewing these, predicting additional questions, and generating and posting their own responses.

\section{Answering the How}

Once faculty and staff understood why and what information they were being asked to report, they tended to be much more amenable to the "How?" discussion: How do I report or oversee the reporting of data? What is the mechanism by which I record and share this information? Therefore, our meetings with faculty and staff typically concluded by addressing the technical aspects of reporting data: timelines, mechanisms, etc.

A sub-question was often attached to the initial technical question, which was: How do I report in a way that is feasible given the limited time and energy of faculty and staff? Although faculty and staff tentatively, if not wholly, agreed to the importance of the data, they worried that the requirements of the comprehensive report would be too onerous, subsequently overwhelming faculty and staff time. Therefore, a final point of discussion was to reiterate the institute's commitment to making reporting easier in future years by adopting a single database system that will allow faculty and staff to duplicate and update existing activity records. Survey systems do not retain information, thereby requiring re-entry of same or similar data each year.

While it is beyond the purpose of this article to describe specifics with regards to administering the online tools used to collect data campus-wide, it is helpful to know that to facilitate a single, comprehensive, and feasible request for community engagement and public service activities, the institute has benefited from the use of two online systems at different times. First, we used a survey form using Qualtrics software. This software has been useful because it allows for highly customized survey designs (such as branching - using if/then logic to decide what series of questions to reveal, such as for community engagement versus public service data, or data from an individual project, versus data provided across projects in aggregate), and advanced reporting and analysis features.

ICEE staff (authors) also have designed and used a relational database called The Community Engagement Collaboratory ${ }^{\circledR}$ (licensed to TreeTop Commons, LLC in 2013). This system was designed and successfully used to collect data for several years. (It is currently under development by TreeTop Commons with an expected 2016 release date). The Collaboratory provided additional features and functions to those possible through use of a survey system, such as the ability to create a database in which projects and partnerships could be updated annually, and to provide a public, web-based platform to showcase community engagement project activities and partners. Both Qualtrics and the Collaboratory database were designed to capture all 
data required to identify and describe community engagement and public service activities at UNCG, and serves as the basis for establishing more focused evaluation and assessment efforts.

\section{Conclusion}

Although attention to and pressure for information about community engagement activities and outcomes has increased over the past decade, there remains a high level of unawareness and, in some cases, resistance to providing information about community-university partnerships and public service activities. Resistance to reporting is not simply a community-engagement issue, but a common faculty response to many external requests for data. Increased monitoring and measuring, particularly when requested or required by external entities such as state governments, can be interpreted as challenges to institutional autonomy and academic freedom (Dugan 2006). Ultimately, collecting comprehensive campus-wide data requires support and buy-in from all levels of the university.

In his scholarship on peace building, Lederach (1997) describes the importance of a "middle-range leadership," leaders who occupy the space between formal leadership and the grassroots activities of ordinary citizens. As administrators in a universitywide institute positioned with the Office of Research and Economic Development and reporting directly to the vice chancellor for research and economic engagement, we had access to individuals with formal positions of authority (namely, the vice chancellor, provost and chancellor), as well as to faculty and staff colleagues. Applying Lererach's work to our approach, we found our middle-range leadership and middle-out approach (connecting to top and bottom) to be important for building a positive and sustainable system. Lederach $(1997,41)$ states that such positions are effective because they connect the top and bottom levels; they are part of a broader network that links together various groups, academic institutions, associations or organizations; and they are "typically well recognized and respected within this broader network, and also enjoy the respect of the people from their own region."

Our experience suggests that tracking community engagement and public service, and using the data to tell an accurate and comprehensive story of the institutions' engagement, requires dedicated staff at the middle-range who are capable of providing clear and informed answers to the why, what, and how questions addressed above. This is particularly true in the early phases of establishing the system, as faculty and staff encounter these requests for the first time, making meaning of what is being asked, why it is being asked, and what it requires of them. Our experience also suggests that establishing the mechanisms and protocols for collecting the data (e.g., survey, database) is time intensive, but once the system is in place, the amount of time required is greatly reduced.

Establishing new or refining existing strategies for comprehensive tracking and reporting - on any topic or metric - is a resource-intensive undertaking. In our experience, it required dedicated leadership from someone with administrative 
authority and a connection to executive leadership, faculty leaders, and rank and file faculty in both tenure and non-tenure tracks. It also required day-to-day attention to technical and procedural details of the survey and database tools, the ability to update the FAQs online, and the availability to serve as the first point of contact for questions related to the data initiative. Though data collection conversations and reporting occurred year round, the spring semesters were the most time intensive for data collection as the annual deadline established by ICEE for submitting data was June 1 (to be sure to capture information before faculty left for the summer). Throughout the year, ICEE staff curated a list and then later a database with details about partnerships that were not directly reported by faculty, but instead, discovered in conversations or via online announcements and publications posted in various venues including, research and alumni magazines, faculty and staff newsletters, on-campus research expo pamphlets, and UNCG public and media relations sites. Over time, we have incorporated work-study students to help serve in data capture and entry, which has produced the unintended consequence of raising their awareness and pride of the community-engaged and public service work contributed by their faculty, staff, and peers. This too is a significant outcome to consider as we continue to establish ways to involve students in data-tracking efforts.

As we look to the future, we have identified the need to continually raise awareness, clarify, and update conversations about community engagement and public service (why, what, how) - across all stakeholders. This is particularly pressing in light of rapid turnover of administrators and faculty as the baby boomer generation continues to retire in large numbers (Sugar et al. 2005). We also expect to continue to build and draw upon relationships with other offices including university relations, institutional research, enrollment management, development and advancement, and alumni relations, to facilitate updates and efficiencies across systems and activities. This is already happening at UNCG and other campuses; capital campaigns (for example, Indiana University-Purdue University Indianapolis), student enrollment initiatives (for example, Tulane University), and alumni relations (for example, the Citizen Alum network) have been effectively advanced as a result of connecting to the university's commitment to and activity in and with the community. At UNCG, much of our early work has focused on working with university relations and creating systems to publicly showcase institutional engagement, particularly on the university's website as a way to claim the identity and image of an engaged university through large numbers of projects and partnerships showcased (Janke, Medlin, and Holland 2015).

As a direct result of data collection efforts, UNCG is now able to track and report community engagement and public service data more effectively and systematically. Data collection efforts at UNCG over the last four years have resulted in the identification of hundreds of community engagement and public service activities across every academic unit at the university as well as within the divisions of student affairs, athletics, and continual learning. Analysis of the data showed that UNCG has considerable strengths in four key areas: arts and culture for a vibrant community, education across the lifespan, economic engagement, and healthy communities (encompassing health, safety). As a direct result of this analysis, the vice chancellor of 
research and economic development ultimately established a new statement to succinctly describe the value of UNCG: "supporting healthy lives and vibrant communities." At the start of faculty meetings, whether at the unit or department level, the ICEE director has presented summaries of the faculty members' engagement to "hold up the mirror" to show them how engaged their faculty colleagues really are and to own and build further on that engagement identity. Faculty members are seeing their data used, and they are becoming better participants and partners in the data collection initiative.

In addition to these quantitative outputs, the relationships built through this process have strengthened every aspect of the institute's programming. Each conversation about metrics provided an opportunity for staff to raise awareness around the institute's other initiatives, and to speak with groups of faculty and staff to which we would not have otherwise had access. As a result, we have been able to gather feedback on current and future programming from diverse audiences, and have been included in more core administrative conversations than previous years, allowing us to continue to embed engagement as a core institutional strategy.

This article moves beyond the conversation of what data to collect (see Janke 2014 for an example of system-wide institutional-level metrics) to address the issue of strategies to collect data once the items have been identified. We illuminate the critical questions and sub-questions that are likely to be raised as a campus begins this effort, regardless of the specific data points requested or systems used to collect data. Being able to foreshadow the questions allows the administrators collecting the information to create successful strategies to motivate participation, create a shared understanding, and avoid likely challenges as well as to proactively craft alliances and connections that can increase strategic use of the data provided by faculty and staff regarding their community-university relations and contributions.

\section{References}

Carnegie Foundation for the Advancement of Teaching. n.d. Elective Classification of Community Engagement, classification description.

Dugan, R. E. 2006. "Stakeholders of Higher Education Institutional Accountability." In Revisiting Outcomes Assessment in Higher Education, edited by P. Hernon, R. E. Dugan, and C. Schwartz, 39-62. Westport, CT: Libraries Unlimited.

Holland, B. 2013. "Determining UNCG's Destiny in the Context of Higher Education Change." Keynote address at University of North Carolina at Greensboro, Greensboro, NC, September.

Institute for Community and Economic Engagement (ICEE). 2013. "2012-13 Annual Report.” Retrieved August 31, 2015. http://communityengagement.uncg.edu/ wp-content/uploads/2014/07/2012-13-Annual-ReportInstitute-for-Community-andEconomic-Engagement.pdf. 
Institute for Community and Economic Engagement (ICEE). 2015. Analytics on ICEE's Frequently Asked Questions - 2015 Data Collection. Retrieved from http:// www.google.com/analytics.

Janke, E. 2014. "Rekindle and Recapture the Love: Establishing System-Wide Indicators of Progress in Community Engagement and Economic Development." Michigan Journal of Community Service-Learning 21 (1).

Janke, E., and B. Holland. 2013. "Data Matters! University of North Carolina at Greensboro: Institute for Community and Economic Engagement." Retrieved from http://communityengagement.uncg.edu/wp-content/uploads/2014/07/Data-Matters.pdf.

Janke, E., K. Medlin, and B. Holland. 2015. "Strategic Organizational Change: Managing Institutional Image and Identity through Monitoring and Measuring Systems." Manuscript submitted for publication.

Kellogg Commission. 2001. Returning to Our Roots: Executive Summaries of the Reports of the Kellogg Commission on the Future of State and Land-Grant Universities. Washington DC: National Association of State Universities and LandGrant Colleges.

Lederach, J. P. 1997. Building Peace: Sustainable Reconciliation in Divided Societies. Washington, DC: United States Institute of Peace Press.

Price, K. N., D. A. Gioia, and K. G. Corley. 2008. "Reconciling Scattered Images: Managing Disparate Organizational Expressions and Impressions." Journal of Management Inquiry 17 (3): 173-185.

Sugar, J., K. Pruitt, J. Anstee, and S. Harris. 2005. "Academic Administrators and Faculty Retirement in a New Era.” Educational Gerontology 31 (5): 405-418.

University North Carolina at Greensboro (UNCG). 2009. "Vision and Mission Statement, Strategic Plan, 2009-2014.” Retrieved February 17, 2011. http://provost.uncg.edu/documents/personnel/evaluationPT.pdf.

University North Carolina at Greensboro (UNCG). 2010. "University-Wide Evaluation Guidelines for Promotions and Tenure. University of North Carolina at Greensboro. Section II.B.1.c." Retrieved February 17, 2011. http://provost.uncg.edu/documents/ personnel/evaluationPT.pdf.

Weerts, D. J. 2011. "If Only We Told Our Story Better...: Re-Envisioning StateUniversity Relations Through the Lens of Public Engagement." WISCAPE Viewpoints. Madison, WI: University of Wisconsin-Madison, Wisconsin Center for the Advancement of Postsecondary Education (WISCAPE). 
Weerts, D., and E. Hudson. 2009. "Engagement and Institutional Advancement." New Directions For Higher Education 2009 (147): 65-74.

\section{Author Information}

Emily M. Janke, $\mathrm{PhD}$, serves as the director of the Institute for Community and Economic Engagement at the University of North Carolina at Greensboro where she is also an associate professor of peace and conflict studies. She led the establishment of protocols, practices, and platforms to collect comprehensive, university-wide information at UNCG, served as the chair of the University of North Carolina systemwide initiative to create annual metrics for community and economic engagement, and served on the national advisory review board for the Carnegie Foundation's 2015 application process for the community engagement elective classification.

Kristin D. Medlin, MPA, served as a graduate assistant and then as the founding manager for partnerships and communications in the Institute for Community Engagement at the University of North Carolina at Greensboro from 2011-2015. During this time, she helped to establish the protocols, practices, and platforms for collecting comprehensive, university-wide information about community engagement and public service. She is now the assistant director for postsecondary initiatives at TreeTop Commons and is pursuing a graduate degree in educational research methodology at the University of North Carolina at Greensboro.

Emily M. Janke

Institute for Community and Economic Engagement

University of North Carolina at Greensboro

P.O. Box 26170

Greensboro, North Carolina 27402-6170

E-mail: emjanke@uncg.edu

Telephone: 336-256-2578

Kristin D. Medlin

TreeTop Commons, LLC

3001 Charolais Drive

Greensboro, North Carolina 27406

E-mail: kdmedlin@uncg.edu

Telephone: 336-907-6921 


\section{Appendix}

\section{FREQUENTLY ASKED QUESTIONS}

Posted on the Institute for Community and Economic Engagement's website (2015).

See more at: http://communityengagement.uncg.edu/2015datafaqs/.

\section{Data Collection Basics}

- Who should report data?

- Can I ask my administrative assistant to complete this information on my behalf?

- What if I have a lot of different activities to report?

- How is the data being collected?

- What is the deadline for providing data?

- Who is leading the data collection effort?

- I'm having trouble with the Qualtrics survey - who can I call for assistance?

- Can I save a copy of my survey results for my own records?

- What about the Collaboratory?

- How will the data I report be used by UNCG?

- What "Counts" and What Doesn't?

- What is Community Engagement?

- What is Public Service?

- Who "counts" as community?

- Who "counts" as a partner?

- For my activity, I worked with someone else on campus - should I be worried about them redundantly reporting the same activity?

- We have an activity that happens between May 30th - June 30th, 2015 - should we report this data?

- What kinds of activities should be reported?

- I oversee student co-curricular community service activities, events, or programs should these be reported?

- Should I report my service on a community board, media interviews, or invited talks?

- Should I report music, theatre, dance, or other kinds of performances? What about public lectures, camps, or other events available to the public?

- I jury exhibitions for other institutions - should this be reported?

- I host a professional development/continuing education event available to the community - should this be reported?

- I supervise student placements - should these be reported?

- I teach a project-based course in which my students complete projects in community settings or in collaboration with community organizations - should these be reported?

- I'm worried about asking my students to report data directly - will I be able to review it?

- Are there any FERPA or HIPPA concerns with student-reported data? 


\section{Select FAQ Responses}

- WHO SHOULD REPORT DATA?

- All UNCG faculty and staff who have community engagement and/or public service activities. These activities may occur as part of your teaching, scholarship, community outreach, or professional programming work roles at UNCG.

- Students MAY report data in special cases - please see the question on student placements and course projects below for more details.

- CAN I ASK MY ADMINISTRATIVE ASSISTANT TO COMPLETE THIS INFORMATION ON MY BEHALF?

- We have made it possible for others in your unit to provide information about your community engagement and public service on your behalf. This could include administrative assistants, graduate students, etc. Please keep in mind that it will be difficult for these individuals to complete the survey on your behalf, as there are a number of required fields - and nobody knows your projects better than YOU!

- WHAT IF I HAVE A LOT OF DIFFERENT ACTIVITIES TO REPORT?

- This survey collects data on an activity-by-activity basis. Please complete one survey per activity. Each "activity" describes the key elements - who, what, where, when, and to what end - of a project, course, program, or other type of community-based or -engaged initiative.

- HOW IS THE DATA BEING COLLECTED?

- Data is collected via an online Qualtrics survey that is available online here.

- WHO IS LEADING THE DATA COLLECTION EFFORT?

- Provost Dana Dunn has asked the Institute for Community and Economic Engagement (ICEE) to lead the effort to capture descriptions of activities university-wide that are provided to, for, or with individuals, groups, and organizations outside of UNCG through public service or community engagement efforts.

- HOW WILL THE DATA I REPORT BE USED BY UNCG?

- We'll be sure to share your great work with others. Your data will help inform work not only with reporting, assessment, and accreditation, but also with university relations, development/advancement, university strategic planning, professional development planning, and convenings and referrals. By knowing who is doing what, where, and with whom, we'll be able to connect people and organizations to each other who are doing similar work.

- WHAT IS COMMUNITY ENGAGEMENT?

- Community engagement is a process by which UNCG works with community partners through mutually beneficial partnerships to co-create activities guided by collaborative, reciprocal co-planning and co-implementation. The exchange of expertise and ideas between academic and external community partners leads to co-creation of knowledge and activities that generate benefits for the academic institution, as well as benefits articulated by community partners.

- Visit http://communityengagement.uncg.edu/definitions/ for more detailed definitions of community-engaged teaching, community-engaged scholarship, and more! 
- WHAT IS PUBLIC SERVICE?

- Public service is an activity through which UNCG provides expertise, resources, and services to or for community individuals, groups, organizations, and the general public. External entities may invite, host, attend, participate, and even benefit from the activity, but the primary responsibility for the design, delivery, and assessment of the activity is shaped by the academic institution. It is important to note that personal volunteerism and professional service/service to the discipline, department, and institution should not be recorded as part of this request.

- WHO "COUNTS" AS COMMUNITY?

- Although UNCG is certainly a member of the community, we use community to mean individuals, groups, and organizations external to campus. Our community extends beyond the local to include regional, state, national, and global partners and may come from a variety of sectors, including, but not limited to, nonprofits, businesses, civic agencies, and schools.

- WHO "COUNTS" AS A PARTNER?

- We know that it can sometimes be difficult to determine who should be listed as a partner on your activity. Consider these guidelines:

- Do not consider academic/disciplinary associations.

- Do not consider funding entities here, UNLESS they are involved in the activity beyond providing dollars (e.g., planning, design, implementation, evaluation). You can identify funding entities in a different section of the survey.

- Do not consider patients, teachers, students or other participating individuals or sites as partners.

- Other universities and colleges can be involved, but should not be the sole participants or partners in this activity.

- WE HAVE AN ACTIVITY THAT HAPPENS BETWEEN MAY 30TH - JUNE 30TH, 2015 - SHOULD WE REPORT THIS DATA?

- Yes! We expect that there will be a few summer programs/camps that will take place during the last month of the 2014-15AY. While we are requesting that data be provided prior to May 30th for most activities (we need time to process and analyze all that data!), we will leave the survey open for those few individuals/ groups who need to report data on activities that happen in June.

- WHAT KINDS OF ACTIVITIES SHOULD BE REPORTED?

- Keep in mind that the data reported here should ONLY reflect work you conduct/ coordinate/represent as part of your professional role with UNCG. While many faculty and staff serve in a number of engagement/service roles as a public citizen (e.g., coaching their child's soccer team, volunteering at church, or involvement with philanthropic groups), UNCG cannot share those activities as part of its overall impact.

- I OVERSEE STUDENT CO-CURRICULAR COMMUNITY SERVICE ACTIVITIES, EVENTS, OR PROGRAMS - SHOULD THESE BE REPORTED?

- Yes! This data is critical for UNCG's application to the President's Honor Roll. For the purposes of this request, only student co-curricular activities that take place as part of an official UNCG program or initiative should be reported (i.e., students' personal volunteerism, or volunteerism that is not part of a UNCG program or event, should not be included). Co-curricular service information 
should be reported by faculty or staff supervisors, advisors, or mentors as this ensures the veracity of the data.

- SHOULD I REPORT MY SERVICE ON A COMMUNITY BOARD, MEDIA INTERVIEWS, OR INVITED TALKS?

- This initiative collects institutionally offered programs, courses, and initiatives. While individual activities connected to serving on community boards, media interviews, invited talks, and expert testimony provide essential contributions to the community, we are not collecting this level of detail at this time (this data may be reported in faculty/staff annual reports). If these roles are connected to one of these institutionally offered programs, they may be identified within the activity record.

- SHOULD I REPORT MUSIC, THEATRE, DANCE, OR OTHER KINDS OF PERFORMANCES? WHAT ABOUT PUBLIC LECTURES, CAMPS, OR OTHER EVENTS AVAILABLE TO THE PUBLIC?

- Yes! Rather than identifying each event individually, you may choose to report this data in the aggregate. Examples include music, theatre, or dance performances; book readings; athletic events; speaker series/public lectures; or other recurring outreach events. For example, the University Performing Arts Series is made up of fifteen events that are offered over the course of the year. You may choose to report each performance as a separate activity, or you may choose to complete ONE activity that summarizes the details of the entire series in aggregate.

- I TEACH A PROJECT-BASED COURSE IN WHICH MY STUDENTS COMPLETE PROJECTS IN COMMUNITY SETTINGS OR IN COLLABORATION WITH COMMUNITY ORGANIZATIONS - SHOULD THESE BE REPORTED?

- Yes! We believe that supervised student work in community is important to capture as it is a direct reflection of your teaching role at UNCG. These courses vary in style - in some courses students focus on just one activity/partner, while in other courses, students split into teams and work with multiple partners on multiple projects. However, it is up to you to decide how meaningful this data is and how feasible it is to report. You might consider one of the three reporting options outlined in the question above. 